- Original Article

\title{
The Intervening Role of Alexithymia in the Relationship between Attachment Styles and Test Anxiety among Gifted High School Students
}

\author{
Esfandiar Sepahvand ${ }^{1}$, Ali Zakiei ${ }^{2, *}$, Keivan Rafieian ${ }^{3}$, Saeid Roumani ${ }^{4}$, Saeid Komasi ${ }^{5}$, Soheyla Reshadat ${ }^{2}$ \\ 'Department of Educational Psychology, Shahid Chamran University, Ahvaz, Iran \\ ${ }^{2}$ Social Development and Health Promotion Research Center, Kermanshah University of Medical Sciences, Kermanshah, Iran \\ ${ }^{3}$ Department of Educational Psychology, Tabriz University, Tabriz, Iran \\ ${ }^{4}$ Department of Curriculum Development, Kharazmi University, Tehran, Iran \\ ${ }^{5}$ Cardiac Rehabilitation Center, Imam Ali Hospital, Kermanshah University of Medical Sciences, Kermanshah, Iran
}

Background: Given the importance of test anxiety among gifted students, the present study was conducted to assess the intervening role of alexithymia in the relationship between test anxiety and attachment styles.

Methods: By means of simple random sampling, 300 participants were selected out of all the students at two high schools in Khorramabad, which are affiliated with the Iranian National Organization for Development of Exceptional Talents (SAMPAD). Test anxiety, alexithymia, and attachment style questionnaires were used for data collection. Pearson correlation and path analysis tests were used to analyze the data.

Results: The results showed a positive relationship between test anxiety and avoidant and anxious attachment styles. Alexithymia and test anxiety were also positively related. Moreover, the results indicated that $12 \%$ of changes in test anxiety were explained by avoidant and anxious attachment styles as well as alexithymia. The relationship between the avoidant attachment style and test anxiety was 0.06 through alexithymia. However, no significant relationship between anxious attachment and test anxiety through alexithymia was found.

Conclusion: The avoidant attachment style leads to test anxiety when the level of alexithymia increases in an individual.

Keywords: Test Anxiety; Attachment Style; Alexithymia 


\section{INTRODUCTION}

Test anxiety is characterized by an emotional state involving fear and worry about the situations that an individual may face during performance evaluation. These situations are mostly encountered in educational areas. ${ }^{1)}$ Some researchers have confirmed that test anxiety is related to poor performance in school assignments. ${ }^{2-5)}$

It is therefore necessary to carry out research on test anxiety. This study has focused on the relationship between attachment styles and test anxiety. Attachment style, which involves primary childhood experiences with parents or the type of parentchild emotional relationship, is another main factor that has been considered by psychologists in recent years. ${ }^{6}$ Researchers usually view attachment as an affective bond between a growing child and its mother that begins at birth. However, its effects are not just confined to an individual's childhood and can cover all life stages, even through old age. ${ }^{7)}$ Each group of parents, based on their own personality and psychological characteristics, treat their children differently from others. This variety in parents' educational and behavioral methods can lead to the formation of three attachment styles, including (1) safe, (2) avoidant unsafe, and (3) ambivalent unsafe. ${ }^{8)}$ Here, it may be claimed that the relationship between a caregiver and child is the most important principle in the development of human personality as emphasized by psychologists. ${ }^{9)}$

According to Bowlby, ${ }^{8)}$ most personality disorders and neuroses are due to a child's deprivation of their mother's care or instability in their relationship. ${ }^{10,11)}$ Most researchers have also confirmed a relationship between attachment styles and mental disorders. ${ }^{12-15)}$

Some studies have pointed to the positive relationship between the anxious attachment style and social anxiety. ${ }^{16)} \mathrm{A}$ positive relationship between the ambivalent attachment style and test anxiety ${ }^{17)}$ has also been confirmed in some studies.

The second factor studied in the present research was alexithymia. Researchers define alexithymia as a person's inability to identify and use verbal language to describe feelings. ${ }^{18)}$ Alexithymia is a multiple personality feature associated with problems in the identification and description of objective emotions, limited mental imaging potential, and an external cognitive orientation. ${ }^{19)}$ Many earlier studies have emphasized that this failure in regulating one's emotions is associated with the appearance of psychopathological symptoms. ${ }^{20)}$ Some have reported that patients with alexithymia showed high levels of anxiety and depression. ${ }^{21)}$ The relationships between alexithymia and depression, ${ }^{22)}$ anxiety, ${ }^{23)}$ and a number of other psychosomatic disorders ${ }^{24-26)}$ have been verified in many studies.

However, since attachment styles are formed at birth and are difficult to change, the relationship between test anxiety and attachment styles and alexithymia remains questionable. We therefore searched for an intervening variable in the relationship between attachment styles and test anxiety in the present study. After considering various theoretical principles and earlier researches, further study on the alexithymia variable appeared necessary, since test anxiety may be developed as an emotion and it is possible to teach strategies for emotional regulation. Furthermore, since gifted students have their own specific conditions and serve as national capitals, more attention should be paid to the issue of test anxiety in this subgroup. The present research was therefore conducted to study the intervening role of alexithymia in the relationship between attachment styles and test anxiety.

\section{METHODS}

\section{Design and Background}

This research used a descriptive method. As this research studies causes and effects, it also uses a causal method considering the relationship between its variables. Using simple random sampling, 300 participants were selected out of all the students at two high schools in Khorramabad, which are affiliated with the Iranian National Organization for Development of Exceptional Talents (SAMPAD). This sample included 152 female students and 148 male students, with a mean age of $16.30 \pm 0.77$ years. A sample size of 300 was determined based on Morgan's table. However 325 individuals were selected for the sample due to the possibility of fallouts and alterations in the questionnaires. Research objectives were clarified for the sample members and they answered the questions with satisfaction. The respondents completed the questionnaires individually in the presence of the interviewers. The questionnaires were subsequently collected and analyzed through Pearson correlation and path analysis tests with IBM SPSS ver. 21.0 (IBM Co., Armonk, NY, USA) and Amos ver. 18.0 (SPSS Inc., Chicago, IL, USA) software.

\section{Research Tools}

The following questionnaires were used for data collection.

\section{1) Toronto Alexithymia Scale- 20}

This scale is a 20 -item test that measures three subscales of 'difficulty identifying feelings (DIF)' (7 items), 'difficulty describing feelings (DDF)' (5 items), and 'externally-oriented thinking (EOT)' (8 items) on the five-point Likert scale ranging from 1 (strongly disagree) to 5 (strongly agree). An overall score is calculated to determine general alexithymia. The psychometric features of the Farsi version of the Toronto Alexithymia Scale-20 (FTAS-20) have been studied and confirmed in numerous researches. ${ }^{27)}$ In the Farsi version of the FTAS-20, Cronbach's alpha coefficients for general alexithymia and its subscales of DIF, DDF, and EOT were respectively calculated as $0.85,0.82,0.75$, 
and 0.72 , which denotes the proper internal consistency of the scale. The test-retest reliability of the FTAS-20 in a sample size of 67 individuals with an interval of four weeks was confirmed as $r=0.80$ to $r=0.87$ for general alexithymia and its different subscales. The concurrent validity of the FTAS-20 was studied and confirmed in terms of correlation between its subscales with emotional intelligence, psychological well-being, and psychological frustration. The results from Pearson correlation analysis showed a significant correlation between the scores obtained by the subjects in the general alexithymia scale and emotional intelligence, psychological well-being, and psychological frustration. The correlation coefficients between alexithymia subscales and the foregoing variables were also significant. The results of confirmatory factor analysis have also reported the existence of triple factors such as DIF, DDF, and EOT in the Farsi version of the FTAS-20. ${ }^{27)}$ In the present research, Cronbach's alpha was determined as 0.75 for this questionnaire.

\section{2) Attachment styles questionnaire}

This test, designed by Hazan and Shavr in 1987, is a self-report tool based on the Ainsworth triple attachment style (i.e., safe, avoidant, and ambivalent), hypothesizing that attachment styles similar to those of children can also be found in adult relationships. ${ }^{28)}$ The scale involves descriptions of an individual's feelings about their perceptions of the current relationships with important people in their life. Taheri ${ }^{29)}$ in 2009 determined the validity of this questionnaire as 0.55 to 0.74 through internal consistency of the attachment styles, and has reported its reliability by means of the test-retest method as $r=0.84$ for the safe attachment style and $\mathrm{r}=\mathbf{0 . 7 8}$ for ambivalent unsafe and avoidant styles. In this research, Cronbach's alpha was calculated as 0.73 for the questionnaire.

\section{3) Sarason's test anxiety questionnaire}

This questionnaire was designed by Sarason in 1984 to measure test anxiety and includes 25 items. The subject must indicate whether each item is correct or incorrect. An individual's psychological states and psychological experiences may there- fore be assessed before, during, and after the test through a self-report method. Selecting the correct choice denotes anxiety, with a corresponding score of 1 . Conversely, an incorrect choice in each item corresponds with a score of 0 and indicates a lack of suffering from anxiety. In a previous study, Yazdani ${ }^{30}$ ) in 2012 has reported Cronbach's alpha coefficient for this questionnaire as 0.88 , an internal consistency of 0.95 , and its standard validity as 0.72 . In another study conducted by Aghajani et al. ${ }^{31)}$ in 2014, Cronbach's alpha coefficient and the consistency of this questionnaire have been reported as 0.77 and 0.71 , respectively. In the present study, Cronbach's alpha coefficient was determined as 0.70 for the questionnaire.

\section{RESULTS}

In Table 1, the mean and standard deviation of the research variables are presented. Correlation coefficients between alexithymia and attachment styles with test anxiety are offered in Table 2.

Table 2 shows no significant correlation between the safe attachment style and test anxiety. However, a correlation coefficient of 0.17 was found between the avoidant attachment style and test anxiety, which was significant at the $\mathrm{P}<0.004$ level. Additionally, a correlation coefficient of 0.27 was found between the anxious attachment style and test anxiety, which was significant at the $\mathrm{P}<0.001$ level. A correlation coefficient of 0.28 was found between alexithymia and test anxiety, which was significant at $\mathrm{P}<0.001$.

Analysis of the results indicated a correlation coefficient of 0.21 between the avoidant attachment style and alexithymia,

Table 1. Mean and standard deviation values of research variables for each sex

\begin{tabular}{lccc}
\hline Variable & Female & Male & Total sample \\
\hline Test anxiety & $11.95 \pm 4.68$ & $10.31 \pm 4.35$ & $11.14 \pm 4.59$ \\
Safe attachment style & $14.79 \pm 4.21$ & $16.05 \pm 4.53$ & $15.41 \pm 4.41$ \\
Avoidant attachment style & $9.10 \pm 4.57$ & $10.34 \pm 4.88$ & $10.17 \pm 4.72$ \\
Anxious attachment style & $13.91 \pm 5.34$ & $15.68 \pm 5.17$ & $14.78 \pm 5.32$ \\
Alexithymia & $54.27 \pm 12.37$ & $55.21 \pm 10.23$ & $54.73 \pm 11.35$
\end{tabular}

Table 2. Correlation coefficients between test anxiety and alexithymia and attachment styles

\begin{tabular}{|c|c|c|c|c|c|c|}
\hline \multirow{2}{*}{ Variable } & \multicolumn{2}{|c|}{ Female } & \multicolumn{2}{|c|}{ Male } & \multicolumn{2}{|c|}{ Total sample } \\
\hline & r & P-value & r & P-value & r & P-value \\
\hline \multicolumn{7}{|l|}{ Attachment styles } \\
\hline Safe & -0.11 & 0.17 & 0.09 & 0.26 & -0.04 & 0.52 \\
\hline Avoidant & 0.22 & $0.006^{\star *}$ & 0.03 & 0.11 & 0.17 & $0.004^{* *}$ \\
\hline Anxiety & 0.33 & $0.001^{\star *}$ & 0.28 & $0.001^{* *}$ & 0.27 & $0.001^{* *}$ \\
\hline \multicolumn{7}{|l|}{ Alexithymia } \\
\hline Difficulty identifying feelings & 0.47 & $0.001^{\star *}$ & 0.40 & $0.001^{\star *}$ & 0.44 & $0.001^{\star *}$ \\
\hline Difficulty describing feelings & 0.19 & $0.02^{*}$ & 0.07 & 0.40 & 0.13 & $0.02^{\star}$ \\
\hline Externally-oriented thinking & -0.09 & 0.26 & -0.12 & 0.16 & -0.013 & $0.03^{*}$ \\
\hline Total & 0.33 & $0.001^{\star \star}$ & 0.24 & $0.003^{\star *}$ & 0.28 & $0.001^{* *}$ \\
\hline
\end{tabular}

${ }^{*} \mathrm{P}<0.05 .{ }^{* *} \mathrm{P}<0.01$. 
Table 3. Path analysis for the effect of attachment styles on test anxiety through alexithymia

\begin{tabular}{|c|c|c|c|c|c|c|}
\hline \multirow{2}{*}{ Variable } & \multicolumn{3}{|c|}{ Direct coefficients } & \multicolumn{3}{|c|}{ Indirect coefficients } \\
\hline & B & $\beta$ & P-value & B & $\beta$ & P-value \\
\hline Avoidant attachment style & 0.27 & 0.11 & 0.057 & 0.05 & 0.06 & $0.001^{* *}$ \\
\hline Anxiety attachment style & 0.26 & 0.26 & $0.001^{\star *}$ & 0.02 & 0.02 & 0.07 \\
\hline
\end{tabular}

${ }^{* \star P} \mathrm{P}<0.01$

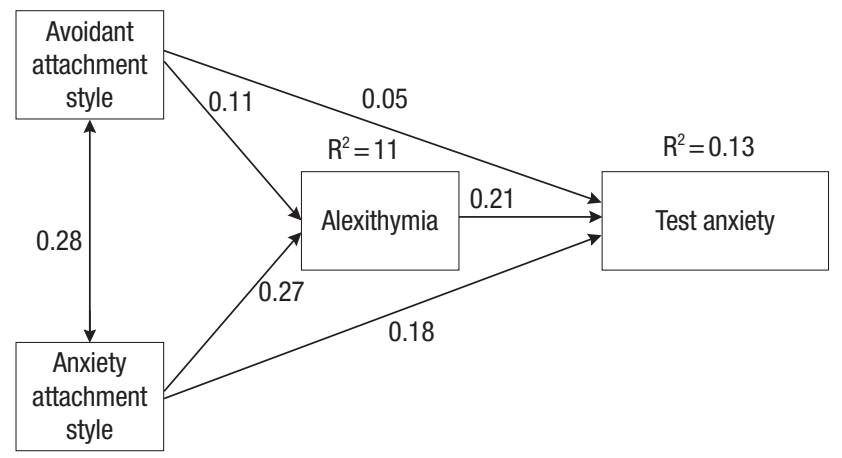

Figure 1. Diagram of the suggested research model.

and a correlation coefficient of 0.31 between the anxious attachment style and alexithymia, which were both significant at the $\mathrm{P}<0.001$ level. However, no significant correlation was observed between attachment style and alexithymia.

Path analysis was used for studying the effect of attachment styles on test anxiety through mediation of alexithymia. An analysis of the results is briefly presented in Table 3 .

In Table 3, path analysis results showed that the standard coefficient of a direct path between the avoidant attachment style and test anxiety was not significant. However, the standard coefficient of a direct path between anxious attachment and test anxiety was 0.26 . Consequently, the non-standard coefficient between the avoidant attachment style and test anxiety through alexithymia was 0.06 , which was significant at the $\mathrm{P}<0.001$ level. The results also indicate that avoidant and anxious attachment styles account for 11 percent of the changes in alexithymia. Moreover, avoidant and anxious attachment styles along with alexithymia account for 12 percent of the changes in test anxiety. The diagram for the suggested research model is presented in Figure 1.

\section{DISCUSSION}

The present research was conducted to study the intervening role of alexithymia in the relationship between attachment styles and test anxiety. The results showed a positive relationship between test anxiety and the avoidant and anxious attachment styles. This means that individuals exhibiting avoidant or anxious attachment styles may experience a higher level of test anxiety. The results also indicated no relationship between the safe attachment style and test anxiety. Moreover, the results of this research are inconsistent with those of earlier studies that show a negative relationship between the safe attachment style and anxiety disorders. ${ }^{12-17)}$ Therefore, the current research somewhat confirms Bowlby's theory. ${ }^{10)}$

These results may be better explained with the premise that a lack of proper interaction between child and mother, together with affective and emotional deprivation during childhood, may lead to the formation of an unsafe attachment style. This may cause the individual to feel the absence of support for his or her care and growth needs during adolescence. Such adolescents come to know their parents as under-confident, which consequently creates a large gap between them. In these conditions, a lack of sympathy during stressful situations such as tests is completely tangible. In other words, these individuals feel that there is no psychologically safe support for them under such conditions, which may cause them to suffer from a higher level of anxiety.

Elsewhere, the results showed a positive relationship between alexithymia and test anxiety. In other words, the higher the level of alexithymia in a person, the more anxiety they may experience. Conversely, the lower the level of alexithymia in a person, the less anxiety they may suffer. No research has been conducted on the relationship between alexithymia and test anxiety, however many studies have demonstrated a relationship between alexithymia and anxiety disorders. ${ }^{20-25,27)}$

Students who express their emotions in due time (i.e., have lower amounts of alexithymia) may be better suited to cope with test anxiety, since they can share their feelings about a test and its emotional conditions with others. In the context of the present findings, it may be argued that alexithymia is a cognitive affective feature in which the sufferer is unable to regulate and perceive their emotions. When emotional information cannot be perceived and evaluated in cognitive processing, individuals may become confused and frustrated from cognitive and affective aspects, and this inability may disorganize their affects and cognitions. Because of emotional unawareness and inability to process their feelings cognitively, these individuals cannot usually identify, perceive, or describe their emotions and have limited ability to cope with stressful situations such as tests. One method for controlling stress, especially with regard to negative emotions, is to display the emotions arising from stress. If such emotions are not discharged and the person does not verbally express their negative feelings, the psychological aspects of the emotional expression and mental perturbation 
systems (including anxiety) may increase. Students who perceive their feelings and express their emotional states more effectively may encounter test settings better than others, and usually experience lower test anxiety.

The results showed that anxious and avoidant attachment styles along with alexithymia account for 12 percent of the changes in test. The relationship between the avoidant attachment style and test anxiety was determined as $\beta=0.06$ through alexithymia. However, the relationship between the anxious attachment style and test anxiety through alexithymia is not significant.

People with avoidant attachment styles commonly refuse to approach others. If these individuals suffer from alexithymia, their refusal tendency increases because they have difficulty expressing their emotions. Therefore, in order for these individuals to somewhat control their test anxiety, we must teach them how to regulate their emotions.

In conclusion, people with avoidant or anxious attachment styles suffer from higher levels of test anxiety. In individuals suffering from alexithymia, test anxiety is exacerbated. Moreover, the causal relationship between the avoidant attachment style and test anxiety through alexithymia is significant. In other words, the avoidant attachment style leads to test anxiety when an individual's level of alexithymia increases. By teaching the students how to regulate their emotions and reduce alexithymia, we can eliminate the effect of the avoidant attachment style on test anxiety.

Because this research was carried out on gifted high school students who have their own special conditions and serve as national capitals, more attention should be devoted to test anxiety in this population. School authorities and counselors should consider the role of attachment styles and alexithymia in the students. Furthermore, since the present study was conducted among gifted high school students in a typical Iranian city, its results should be carefully generalized to students in ordinary schools and other communities. We suggested that similar studies be conducted among ordinary students in future so that the results can be compared.

\section{CONFLICT OF INTEREST}

No potential conflict of interest relevant to this article was reported.

\section{REFERENCES}

1. Brown LA, Forman EM, Herbert JD, Hoffman KL, Yuen EK, Goetter EM. A randomized controlled trial of acceptance-based behavior therapy and cognitive therapy for test anxiety: a pilot study. Behav Modif 2011;35:31-53.

2. Ackerman PL, Heggestad ED. Intelligence, personality, and interests: evidence for overlapping traits. Psychol Bull 1997;121:219-45.

3. Hembree R. Correlates, causes, effects, and treatment of test anxiety. Rev Educ Res 1988;58:47-77.

4. Seipp B. Anxiety and academic performance: a meta-analysis of findings. Anxiety Res 1991;4:27-41.

5. Javanbakht N, Hadian M. The effects of test anxiety on learners' reading test performance. Procedia Soc Behav Sci 2014;98:775-83.

6. Bayrami M, Fahimi S, Akbari E, Amiri-Pichakolaei A. Predicting marital satisfaction on the basis of attachment styles and differentiation components. J Fundam Ment Health 2012;14:64-77.

7. Shaker A, Fathi-Ashtiani A, Mahdavian A. The relationship of attachment styles and mental health with marital adjustment in couples. J Behav Sci 2011;5:179-84.

8. Bowlby J. Attachment and loss. Vol. 1. New York: Basic Books; 1969.

9. Yaghoubi R, Azadfallah P, Tabatabaei SK. The relationship between approach/avoidance systems and attachment styles. J Behav Sci 2014; 7:289-95.

10. True MM, Pisani L, Oumar F. Infant-mother attachment among the Dogon of Mali. Child Dev 2001;72:1451-66.

11. Cornell T, Hamrin V. Clinical interventions for children with attachment problems. J Child Adolesc Psychiatr Nurs 2008;21:35-47.

12. Jahanbakhsh M, Amiri S, Molavi H, Bahadori MH. Girls with attachment problems related to maternal attachment. Iran J Psychiatry Clin Psychol 2010;3:15-24.

13. Mickelson KD, Kessler RC, Shaver PR. Adult attachment in a nationally representative sample. J Pers Soc Psychol 1997;73:1092-106.

14. Fonagy P, Leigh T, Steele M, Steele H, Kennedy R, Mattoon G, et al. The relation of attachment status, psychiatric classification, and response to psychotherapy. J Consult Clin Psychol 1996;64:22-31.

15. Burge D, Hammen C, Davila J, Daley SE, Paley B, Lindberg N, et al. The relationship between attachment cognitions and psychological adjustment in late adolescent women. Dev Psychopathol 1997;9:151-67.

16. Ozturk A, Mutlu T. The relationship between attachment style, subjective well-being, happiness, and social anxiety among university students. Procedia Soc Behav Sci 2010;9:1772-6.

17. Ghahvehchi F, Fathi-Ashtiani A, Azadfallah P. The relationship between metacognitive beliefs and students' test anxiety coping styles, given the role of ambivalent attachment. Res Ment Health 2012;6:10-8.

18. Celikel FC, Saatcioglu O. Alexithymia and anxiety in female chronic pain patients. Ann Gen Psychiatry 2006;5:13.

19. Taylor GJ, Bagby RM, Kushner SC, Benoit D, Atkinson L. Alexithymia and adult attachment representations: associations with the five-factor model of personality and perceived relationship adjustment. Compr Psychiatry 2014;55:1258-68.

20. Saarijarvi S, Salminen JK, Toikka TB. Alexithymia and depression: a 1-year follow-up study in outpatients with major depression. J Psychosom Res 2001;51:729-33.

21. Honkalampi K, Hintikka J, Saarinen P, Lehtonen J, Viinamaki H. Is alexithymia a permanent feature in depressed patients?: results from a 6-month follow-up study. Psychother Psychosom 2000;69:303-8.

22. Cox BJ, Swinson RP, Shulman ID, Bourdeau D. Alexithymia in panic disorder and social phobia. Compr Psychiatry 1995;36:195-8.

23. Taylor GJ, Bagby RM. New trends in alexithymia research. Psychother Psychosom 2004;73:68-77.

24. Richards HL, Fortune DG, Griffiths CE, Main CJ. Alexithymia in pa- 
tients with psoriasis: clinical correlates and psychometric properties of the Toronto Alexithymia Scale-20. J Psychosom Res 2005;58:89-96.

25. Karami J, Momeni K, Zakiei A. The relationship between alexithymia, positive affection, and negative affection with the obsessive - compulsive disorder syndrome. UMJ 2013;24:534-42.

26. Zakiei A, Karami J. The relationship between alexithymia, positive affection, and negative affection with mental disorders. Med J Tabriz Univ Med Sci 2013;35:38-45.

27. Zakiei A. The relationship between alexithymia, Ellis irrational beliefs, positive and negative affection on psychiatric disorders among college students in Razi University of Kermanshah, Iran [unpublished master's thesis]. Kermanshah: Razi University; 2012.
28. Bayrami M, Mohammadpour V, Gholamzadeh M, Esmaeili B. Comparison of happiness and willingness to communicate in attachment styles among university students. J Behav Sci 2012;6:105-9.

29. Taheri M. The relationship between maternal attachment styles and social maturity of mentally retarded secondary school male students in Shiraz. Hakim Med J 2009;13:37-9.

30. Yazdani F. Test anxiety and educational performance in female nursing students. Ofogh 2012;1:47-58.

31. Aghajani T, Shoghi B, Naeimi S. Analysis of structural relationships of self-differentiation training with test anxiety and self-efficacy beliefs. Knowl Res Appl Psychol 2014;15:34-43. 